\title{
Preparation, characterization and evaluation of moisturizing and UV protecting effects of topical solid lipid nanoparticles
}

\author{
Shiva Golmohammadzadeh ${ }^{1, *}$, Mohsen Mokhtari', Mahmoud Reza Jaafari² \\ ${ }^{1}$ Nanotechnology Research Center, School of Pharmacy, Mashhad University of Medical Sciences, Mashhad, Iran, \\ ${ }^{2}$ Biotechnology Research Center, Nanotechnology Research Center, School of Pharmacy, Mashhad University of Medical \\ Sciences, Mashhad, Iran
}

\begin{abstract}
Solid lipid nanoparticles (SLN) were recently proposed as carriers for various pharmaceutical and cosmetic actives. These lipid nanoparticles can act as moisturizers and physical sunscreens on their own. Therefore, the full potential of these carriers has yet to be determined. The present study was aimed to determine and compare moisturizing and UV-protecting effects of different solid lipid nanoparticles (SLN) prepared by different solid lipids including Glyceryl monostearate (GMS), Precirol ${ }^{\circledR}(\mathrm{P})$ and cetyl palmitate (CP) as carrier systems of moisturizers and sunscreens. The influence of the size and matrix crystallinity of the solid lipids on the occlusive factor, skin hydration and UV-protection were evaluated by in vitro and in vivo methods. The SLN were prepared by high-shear homogenization and ultrasound methods. Size, zeta potential and morphological characteristics of the samples were assessed by transmission electron microscopy (TEM) and thermotropic properties with differential scanning calorimetry (DSC) technique. Results of the assessments showed that SLN-CP significantly increases skin hydration and UV-protection, compared to SLN-GMS and SLN-P. It was demonstrated that the size of SLN, crystallinity index of solid lipid in SLN and probably other mechanisms besides the occlusive factor can influence skin hydration and UV-protection indices. Furthermore, findings of the assessments demonstrated significant difference between in vitro and in vivo assessments regarding occlusive factor and moisturizing effects. Findings of the present study indicate that the SLN-CP could be a promising carrier for sunscreens and moisturizers.
\end{abstract}

Uniterms: Solid lipid nanoparticles/moisturizing effects. Solid lipid nanoparticles/UV protecting.

\begin{abstract}
Nanopartículas lipídicas sólidas (NLS) foram, recentemente, propostas como carreadores de vários ativos cosméticos e farmacêuticos. Essas nanopartículas lipídicas podem atuar como hidratantes e protetores solares físicos por si só. Assim sendo, determinou-se o potencial desses carreadores. Os objetivos do presente estudo foram determinar e comparar os efeitos hidratantes e protetores contra UV das diferentes partículas lipídicas sólidas (NLS) preparadas com diferentes lipídios sólidos, incluindo o monoestearato de gligerila (MSG), Precirol ${ }^{R}(\mathrm{P})$ e palmitato de cetila (PC) como sistemas carreadores de hidratantes e de protetores solares. A influência do tamanho e da cristalinidade da matriz dos lipídios sólidos no fator oclusivo, na hidratação da pele e na proteção ao UV foi avaliada por métodos in vitro e in vivo. As NLS foram preparadas por homogeneização por alto corte e métodos de ultrassom. Tamanho, potencial zeta e características morfológicas das amostras foram determinados por microscopia de transmissão eletrônica (MTE) e as propriedades termotrópicas, com diferentes técnicas de calorimetria diferencial de varredura (CDV). Os resultados mostraram que NLS-PC aumenta significativamente a hidratação da pele e a proteção ao UV, comparativamente à NLS-MSG e à NLS-P. Demonstrou-se que o tamanho da NLS, índice de cristalinidade do lipídio sólido na NLS e, provavelmente, outros mecanismos além do fator oclusivo podem influenciar a hidratação da pele e os índices de proteção ao UV. Além disso, os resultados mostraram diferença significativa entre as avaliações in vitro e in vivo com relação ao fator oclusivo e aos efeitos hidratantes. Os resultados do presente estudo indicam que NLS-PC poderia ser um carreador promissor para protetores solares e hidratantes.
\end{abstract}

Unitermos: Nanopartículas lipídicas sólidas/efeitos hidratantes. Nanopartículas lipídicas sólidas/ proteção ao UV.

\footnotetext{
*Correspondence: Shiva Golmohammadzadeh, School of Pharmacy, Mashhad University of Medical Sciences, Mashhad, Iran, P.O. Box: 91389-13131.

E mail: golmohamadzadehsh@mums.ac.ir
} 


\section{INTRODUCTION}

Sunlight exposure can be both beneficial and harmful for the human body. It has been known for decades that sunscreens are capable of protecting human body of solar radiation-induced harmful effects (Kullavanijaya et al., 2005; Potard et al., 2000). Since sunscreens should act on the surface of the skin, they should penetrate as little as possible into the viable epidermis, the dermis and into the systemic circulation (Potard et al., 2000).

Several factors are involved in the transdermal delivery of drugs and cosmetic actives, from topically-applied formulations. The penetration and the effectiveness of active compounds through the human skin depends on physicochemical properties of the drug, size of the molecule, drug-delivery system, lipophilicity of components, vehicle and skin hydration which can be influenced by occlusive and other compounds (Verma et al., 2003; Zhai et al., 2002).

Solid lipid nanoparticles (SLN) have been introduced as a novel drug-delivery systems for pharmaceutical drugs and cosmetic active ingredients due to their advantages over conventional formulations (Muller et al., 2000; Wissing et al., 2003a). They are promising carriers as protecting labile active compounds from degradation (Jenning et al., 2001; Muller et al., 2000), releasing active ingredients in a controlled way (Zur Muhlen et al., 1998; Maia et al., 2000), increasing skin water content, (Wissing et al., 2001; Wissing et al., 2002b) and UV-blocking potential as physical sunscreens (Wissing et al., 2001b; Wissing et al., 2002a).

The occlusive property of the SLN is due to its film formation after application through the skin. The extent of the occlusive properties depends on various factors, e.g. particles size, lipid and lipid concentration. The UV protection is based on the UV reflecting and scattering ability like other physical sunscreens (Wissing et al., 2001b; Wissing et al., 2002a; Wissing et al., 2002b).

The occlusive and UV-blocking properties of SLN can introduce them as a promising vehicle for the moisturizer and sunscreen products.

It was observed by other researches that the occlusion factor of lipid microparticles was only $10 \%$, compared to $50 \%$ when using lipid nanoparticles of approximately $200 \mathrm{~nm}$ (Souto et al., 2008). Meanwhile it was found that among Dynasan 112, Compritol 888 ATO and Softisan 154 as solid lipids in SLN; the highest occlusion will be achieved from low melting lipids with highly crystalline particles (Wissing et al., 2003b). These studies do not fully mimic the natural moisture loss conditions and there was no comparison between in vitro and in vivo skin hydration. SLN have been also introduced as a novel carrier for sunscreen ingredients. UV protecting of different lipids in SLN formulations were not investigated by SPF determination in vitro method.

In this study, we investigated and compared the influence of size and crystallinity of different lipid composition in SLN formulations on the occlusion factor using in vitro method and the skin hydration using corneometer in vivo method. UV protection properties of different lipids in SLN formulations were also investigated by Transpore tape ${ }^{3 \mathrm{M}}$ in vitro method.

\section{MATERIAL AND METHODS}

\section{Material}

Glyceryl palmitostearate (Precirol ${ }^{\circledR}$ ATO 5) and glyceryl monostearate (GMS) were gifted by Gattefossé (Pvt. Ltd., France). Cetyl palmitate (CP) and Tween 80 were purchased from Sigma-Aldrich (Deisenhofen Germany). Poloxamer188 was obtained from Uniqema (Everberg, Belgium). All of the original samples were used as their arrival. Water was used a double-distilled water.

\section{Preparation of SLN}

The SLN were prepared by high-shear homogenization and ultrasound method. Precirol ${ }^{\circledR}$ ATO 5, GMS and $\mathrm{CP}(1 \mathrm{~g})$ were melted by heating at $5{ }^{\circ} \mathrm{C}$ above the melting point of the lipids. The aqueous phase was prepared by dissolving tween $80(0.5 \mathrm{~g})$ for GMS and CP, or poloxamer $188(0.5 \mathrm{~g})$ for Precirol ${ }^{\circledR}$ ATO 5 in double-distilled water ( $10 \mathrm{ml}$ of the solution was produced) and that was heated up to the melting point temperature of the lipid phase. Hot aqueous phase was added to the molten lipid phase and homogenized by Diax 900 homogenizer (Heidolph, Germany) for $2 \mathrm{~min}$ at $11,000 \mathrm{rpm}$. The temperature was kept at $5{ }^{\circ} \mathrm{C}$ above the melting point of the lipid. Coarse hot oil in water emulsion obtained was ultrasonicated by Prob Sonicator (Bransonic, USA). The prob sonication was performed at 6 cycles with 30 seconds of sonication separated by intervals of 15 seconds. The obtained nanoemulsions were cooled to room temperature(Kumar et al., 2007; Venkateswarlu et al., 2004).

\section{Characterization of SLN}

\section{Particle size and zeta potentials}

Dynamic light scattering (ZetaSizer Nano-ZS; Malvern Instruments Ltd., United Kingdom) method was used to assess the mean particle size, polydispersity index 
and zeta potential of the SLN formulations. All measurements were performed in triplicate at a temperature of 25 ${ }^{\circ} \mathrm{C} \pm 2{ }^{\circ} \mathrm{C}$ and an angle of $90^{\circ} \mathrm{C}$ to the incident beam. No multi-scattering phenomenon was observed during the assessments.

\section{Transmission electron microscopy (TEM)}

TEM assessment (TEM; CEM 902A; Zeiss, Oberkochen, Germany) was performed to characterize the morphology of SLN formulations. The SLN were diluted 50 times with water and then placed on a carbon-coated copper grid for 30 seconds and the excess water was wiped off by a filter paper. Then $20 \mu \mathrm{L}$ of uranyl acetate $2 \%$ in water covered on SLN and after 30 seconds were wiped off by filter paper. The grid was dried at room temperature and then assessed by TEM (Liu et al., 2007).

\section{Differential Scanning Calorimetry (DSC)}

Melting and recrystallization behavior of crystalline materials were assessed using Mettler DSC $821^{\mathrm{e}}$ (Mettler Toledo, Gießen, Germany. DSC scans of the bulk lipids and SLN formulations were carried out. An empty aluminum pan served as reference. Samples were scanned from $25^{\circ} \mathrm{C}$ to $100^{\circ} \mathrm{C}\left(5^{\circ} \mathrm{C} / \mathrm{min}\right)$ under nitrogen atmosphere $(20$ $\mathrm{mL} / \mathrm{min}$ ); then, the melting point of SLN formulations was compared to the bulk lipid. Before the DSC measurements, the bulk lipids were heated up to $75{ }^{\circ} \mathrm{C}$ and cooled to the room temperature to imitate the production conditions. Analysis was carried out under nitrogen purge (Jenning et al., 2001; Wissing et al., 2002a).

\section{Occlusive Properties Assessment}

For the occlusion test, $100 \mathrm{~mL}$ beakers were filled with $50 \mathrm{~mL}$ water and covered with filter paper (cellulose acetate filter, cutoff size: $4-7 \mu \mathrm{m})$ and sealed. Samples were spread on the filter surface $\left(13.3 \mathrm{mg} / \mathrm{cm}^{2}\right)$ and stored at $32{ }^{\circ} \mathrm{C}$ and $50 \%-55 \%$ Relative Hydration $(\mathrm{PH})$ for $48 \mathrm{~h}$. Beakers covered with filter paper with no sample, were considered as reference. The occlusion factor (F) was calculated according to the following Equation (Eq.1) After $24 \mathrm{~h}$ and $48 \mathrm{~h}$, where $\mathrm{A}$ is the water loss without sample (reference), and B is the water loss with sample. Every experiment was carried out in triplicate (Wissing et al., 2002b; Souto et al., 2004).

$$
F=100 \times((\mathrm{A}-\mathrm{B}) / \mathrm{A})
$$

Eq. 1

\section{Skin hydration measurement using Corneometer}

The moisture content of the skin was measured by a corneometer (Courage, Khazaka, Cologne, Germany) following application of different SLN formulations. The test was carried out on 6 volunteers with normal skin at room temperature (ages were between 20 and 35 years). Before the measurements, subjects were given time to adapt to room conditions without covering the measuring sites. On the day of examination, the skin was not washed and nothing was applied to the skin surface. Subjects were instructed not to apply any preparation to the site to be examined one week before investigation. The corneometer CM 820 was used to determine the humidity level of the stratum corneum by measuring electrical capacitance. All the measured values were expressed as the median of three recordings. The measurements were carried out on exactly the same sites. The measuring place was in the middle of the forearm. In the first instant, the moisture content of the skin without any application of the product was measured, and then the measurement was carried out after $30 \mathrm{~min}$, 2, 3, 6 and 10 hours after application of the sunscreens (Sator et al., 2003).

\section{SPF determination of the formulations using Transpore tape in vitro method}

The principle of this method is based on the measurement of the spectral transmittance of UVR through a sample of a surgical tape which is called Transpore tape with and without the sunscreen applied. This substrate was introduced first by Diffey (Diffey, 2002). SLN formulations and sunscreen standard were applied on the surface of the TransporeTM tape at $2 \mathrm{mg} / \mathrm{cm} 2$. After 15 minutes transmission was measured from $290 \mathrm{~nm}$ to $400 \mathrm{~nm}$ at intervals of $5 \mathrm{~nm}$ at five distinct points. The predicted SPF value was calculated according to the following equation (Eq. 2).

$$
S P F=\frac{\int_{290}^{400} E(\lambda) \cdot S(\lambda) \cdot d \lambda}{\int_{290}^{400} E(\lambda) \cdot S(\lambda) \cdot T(\lambda) \cdot d \lambda}
$$

In this equation: $\mathrm{E}(\lambda)$ : CIE Relative Erythemal Spectral Effectiveness, $S(\lambda)$ : Solar Spectral Irradiance $\left(\mathrm{Wm}^{-2} \mathrm{~nm}^{-1}\right), \mathrm{T}(\lambda)$ : Spectral Transmittance of the sample (as measured on the UV-1000S). Results were reported as mean SPFs and relative standard deviations as percentage of the mean SPF.

\section{Data analysis}

All the experiments of each preparation were repeated three times, and data were expressed as the mean 
value \pm S.D. The statistical data were analyzed using nonparametric with a Tukey-Kramer test. Results with $P$ $<0.05$ were considered statistically significant.

\section{RESULTS AND DISCUSSION}

Three types of SLN were prepared by high-shear homogenization and ultrasound method. Homogenization, followed by ultrasonication, is a simple, reliable and reproducible method for SLN preparation (Venkateswarlu et al., 2004). The process parameters, involved in the preparation of SLN were optimized, including lipid and surfactant (type and concentration), lipid/surfactant ratio, homogenization and sonication time to reduce the size of nanoparticles with narrow size distribution. Physically stable SLN with a narrow size distribution were produced. To obtain stable and smaller SLN, sonication cycles, were varied from 6 to 20 and their effect on particle size was measured. It was obtained that in 12 and 20 cycles, the PI of the SLN distribution was increased with no significant difference in the mean size of the particles. Therefore, 6 cycles were used for the preparations.

The mean diameter (z-average), PI and zeta potential of the bulk population of the particles, were measured by particle size analyzer (PSA), which are shown in Table I.
Among the lipids used, GMS and Precirol produced significantly smaller size of SLN, compared CP. In addition, no significant difference of the size between SLN-GMS and SLN-P were obtained. The difference between the mean particle size and particle size distribution is because of the difference of the type of lipid and emulsifier in different SLN formulations. GMS is a surface active partial glyceride which facilitated emulsification and formed more rigid surfactant films and then improved the longterm stability of SLN (Hou et al., 2003).

Zeta potential can make a prediction about the stability of colloid dispersions. A high zeta potential $(>30 \mathrm{mV})$ can provide an electric repulsion to avoid the aggregation of the particles (Levy et al., 1994). The zeta potentials of SLN-GMS and SLN-P were above $-35 \mathrm{mV}$ which was physically more stable than SLN-CP.

The TEM imaging of SLN-GMS, SLN-CP and SLNP SLN are shown in Figure 1. It was observed all of the SLN formulations exhibited nanometric size, spherical shape and had a narrow size distribution. There was no difference between the particle size of from TEM images and PSA.

To determine the extent of crystallinity, the samples were investigated by differential scanning calorimetry (DSC). Samples were scanned from $25^{\circ} \mathrm{C}$ to $100{ }^{\circ} \mathrm{C}$

TABLE I - The particle size, polydispersity Index (PI) and Zeta potential of different SLN formulations measured by PSA. Data expressed as Mean $\pm \mathrm{SD}(n=3)$ (according to the zeta average), * Statistical significance with SLN-GMS and SLN-CP $(p<0.05)$, not significant with SLN-GMS and SLN-P $(p>0.05)$

\begin{tabular}{lccc}
\hline Formulation & Particle size $(\mathrm{nm})$ & Polydispersity Index $(\mathrm{PI})$ & Zeta Potential $(\mathrm{mV})$ \\
\hline SLN-GMS & $165.3 \pm 5.56$ & $0.24 \pm 0.06$ & $-45.21 \pm 2.1$ \\
SLN-CP & $245.13 \pm 10.32$ & $0.28 \pm 0.01$ & $-27.33 \pm 6.02$ \\
SLN-P & $162.6 \pm 5.3$ & $0.32 \pm 0.01$ & $-36.46 \pm 3.44$ \\
\hline
\end{tabular}
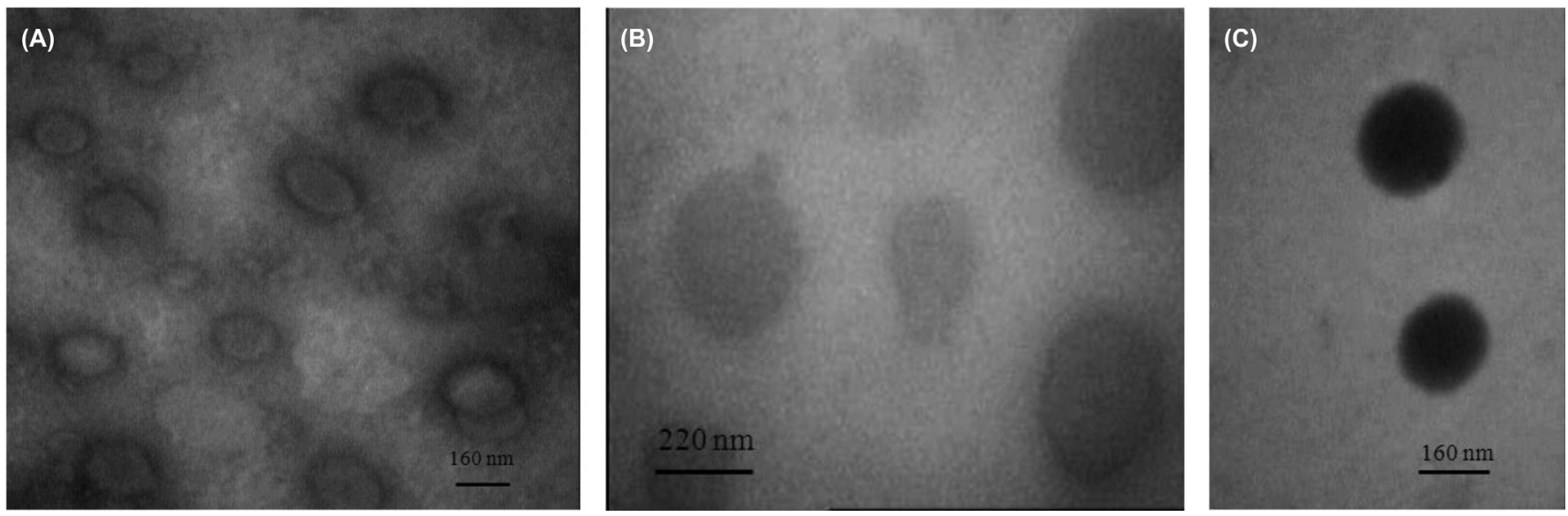

FIGURE 1 - The TEM images of a) SLN-GMS and b) SLN-CP c) SLN-P prepared by high- shear homogenization and ultrasound method. 
$\left(5^{\circ} \mathrm{C} / \mathrm{min}\right)$ and the melting point of SLN formulations was compared to the bulk lipid. The DSC scans of the formulations and the bulk lipids are shown in Figure 2. The melting peak of pure GMS, Precirol and CP proved the solid character of the lipid matrix at room temperature as they are higher than room temperature. The thermogram in Figure 2 (A) and (B) shows that the SLN-GMS and SLN-Precirol depressed the transition temperature of the lipids to a lower temperature and also changed the structure of the peak. The two thermal maxima in the DSC melting of SLN-P curve indicate melting of two different crystalline forms.

The depression of the melting temperature in SLN is due to the lower size and the structure of the SLN. These Figures also showed that the lipid does not recrystallize completely at room temperature however, SLN-CP (Figure 2 (C)) forms highly crystalline lipid nanoparticles and recrystallize completely.

The extent of crystallinity was investigated by DSC. The peak location of SLN-GMS is slightly shifted towards lower temperatures compared to that of the bulk lipid. The recrystallization of the SLN occurred at lower temperatures than the bulk material. The decline of the scan can be explained by the small particle sizes of the SLN formulations, their high specific surface area and the presence of a surfactant (Saupe et al., 2005). It was demonstrated that when the drug is added into SLN, the lipid crystals in an orderly situation were further disrupted which can reduce the crystallization property of nanoparticles. Therefore, the crystallinity of the lipid gradually declines from GMS to SLN-GMS as was shown in Li et al research (Li et al., 2010).

The dependency of the occlusion factor $(F)$ upon the size and crystanillity of the SLN formulations is shown in Figure 3.

No significant difference of the occlusive factor between SLN formulations was observed after 24 and 48h. Increasing the particle size in SLN-CP towards SLNGMS and SLN-P showed a decrease in occlusive factor although the high crystanillity of SLN-CP may enhance the occlusive factor, therefore, the crytanillity effect can modify the size effect on occlusive factor.

In the current study, it was observed that the occlusive factor depends on the size of the particles and crystallinity of the lipids in the SLN formulations. Findings of the study conducted by Wissing et al. 2003b), also confirms that, the dependence of occlusion factor on the particle size of SLN-CP. High occlusion factors of 50-60 obtained when the particle size was lower than $400 \mathrm{~nm}$. Lipid micro-particles were only slightly occlusive .
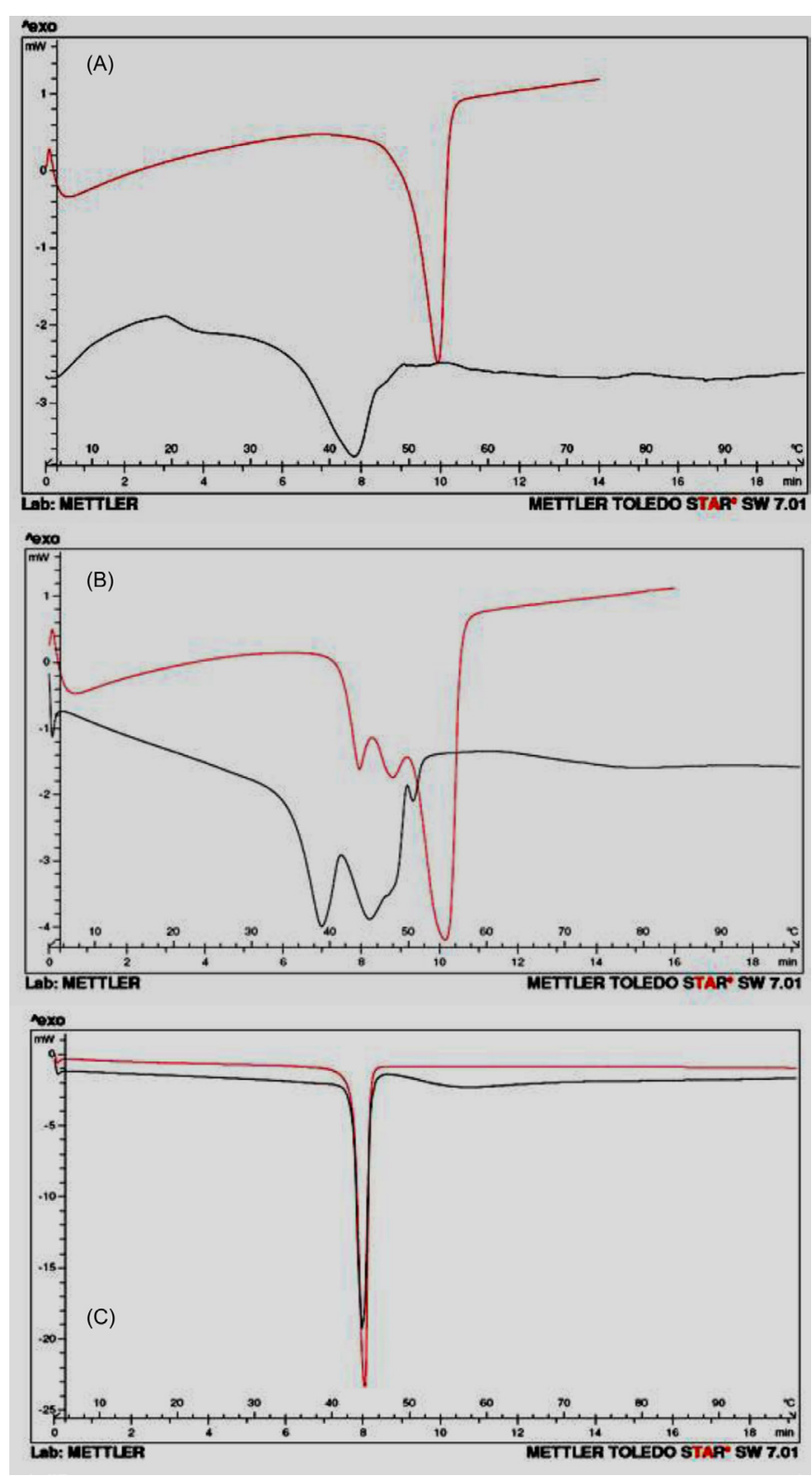

FIGURE 2 - Differential scanning calorimetry thermograms of (A) Red: GMS bulk, Black: SLN-GMS, (B) Red: Precirol, Black: SLN-P and (C) Red: CP, Black: SLN-CP, SLN formulations prepared by high- shear homogenization and ultrasound method.

\section{Skin hydration measurement using Corneometer}

In vitro studies do not fully mimic the natural conditions. Therefore, the in vivo studies have to be carried out (Souto et al., 2008). It was demonstrated that the occlusion factor is dependent upon the sample volume, particle size, crystallinity, lipid concentration and type of colloidal systems (Wissing et al., 2002b; Souto et al., 2004).

The effect of SLN on skin hydration has been further investigated in a blind, placebo-controlled in vivo study 


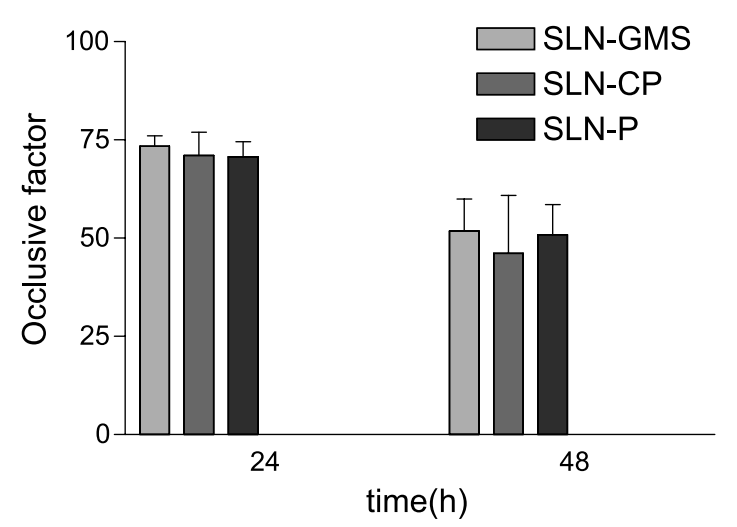

FIGURE 3 - The Occlusion factor of SLN-GMS, SLN-CP and SLN-P after $24 \mathrm{~h}$ and $48 \mathrm{~h}$ as a function of the particle size of the SLN formulations.

and compared to the in vitro results. The skin hydration was measured with a corneometer CM 825 (Courage, Khazaka, Germany).

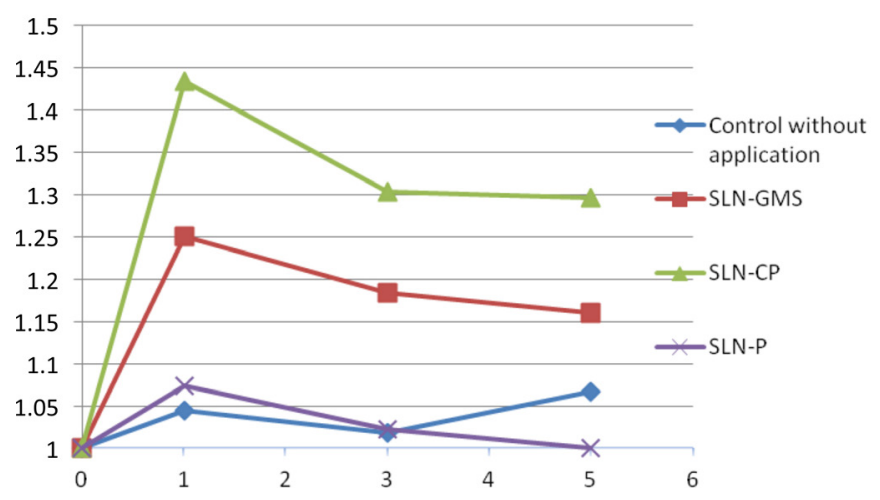

FIGURE 4 - Normalized relative hydration values after application of SLN-P, SLN-CP and SLN-GMS vs. control without application of the product $(n=6)$.

Figure 4 shows the normalized (RCU, Relative Corneometer Units) hydration values for the readings of the reference site measured with corneometer for the SLN formulations at 1, 3 and 5 hours post application vs. baseline without application (control). SLN-CP and SLNGMS significantly increased the moisture content of the skin compared to control point times $(\mathrm{p}<0.01)$. Figure 4 shows that SLN-CP increases skin hydration higher than SLN-P and SLN-GMS. The trend of the curves in all the treatment groups was nearly the same. At 1 hour application, the highest water content was observed for SLN-CP; after 3 hours the moisture contents were decreased in all of the formulations.

In this study, the corneometer was used and calibrated to the base line value for each subject before applying the formulations on the skin. It can be remarked that the extent of hydration of SLN formulations correlates not only with particle size and lipid concentration but also with the degree of crystallinity of the lipid matrix and probably other mechanisms (Wissing et al., 2002b). When applying lipid particles onto the skin, a film layer will be formed, having a surface area which is dependent on the particle size. In small sizes, the dimensions of the air channels will be much smaller; thus, the hydrodynamic evaporation of water will decrease (Wissing et al., 2003b; Souto et al., 2008). An in vivo study showed that addition of $4 \%$ SLN to a conventional o/w cream lead to higher increase of skin hydration compared to the conventional cream after 4 weeks compared to the conventional cream (Wissing et al., 2003b). During the first 30 minutes after application, the level of water content is usually higher than normal. Measurement of water content of skin at this time may result in erroneous data (Alanen et al., 2004; Golmohammadzadeh et al., 2007). Therefore, the first measured time was 30 minute after application. In the current in vivo study it was observed the crystallinity of the lipids has more effective than the size in the sizes below $300 \mathrm{~nm}$. SLN-CP with highly crystalline lipid nanoparticles has shown more hydration on skin than SLN-GMS and SLN-P with does not recrystallize completely.

It was shown that SLN-CP with higher particle sizes and the same occlusive factor demonstrated higher skin hydration. The results of the in vivo study show that the other mechanisms besides the occlusive factor can influence on skin hydration; like Lubrication, smoothness, hygroscopic and emolliency in human.

The ability of SLN formulations to UV radiation blocking was assessed in vitro with Transpore tape method. Figure 5 shows the absorption profiles of SLNCP, SLN-P and SLN-GMS. It can be clearly seen that the absorption profiles varied from one type of solid lipid in SLN formulations to another. The SPF of SLN-GMS, SLN-P and SLN-CP were obtained $1.46 \pm 0.03,2.38 \pm$ 0.09 and $3.31 \pm 0.35$ respectively.

Regarding the Transpore tape in vitro method re-

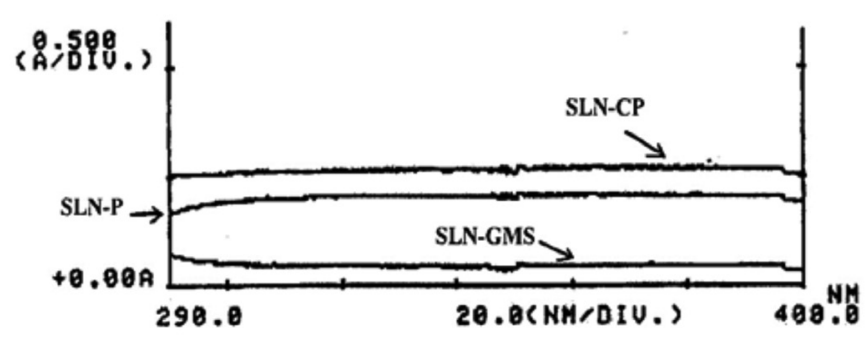

FIGURE 5 - Absorption spectra (280-400 nm) of SLN-CP, SLN-P and SLN-GMS measured by UV spectrophotometer. 
sults, SLN-CP formulations show the highest UV protection abilities because of owing to the high crystallinity of the solid lipid than the other solid lipids. As previously published, increased crystallinity improves UV-blocking effect (Xia et al., 2007). The solid nanoparticles in SLN formulations are able to scatter and reflect UV radiation, leading to a decrease of the outgoing UV light. Thus, incorporation a UV-blocker into a carrier system having a UVblocking effect on its own and thus increasing the overall UV-blocking effect is expected (Wissing et al., 2003a; Wissing et al., 2001a). Cengiz et al showed that $\mathrm{t}$ it is possible to obtain a high UV- protection effect even though the solid lipid content or the amount of the sunscreen agent is decreased. Incorporation of $\mathrm{TiO}_{2}$ as a sunscreen agent into SLN formulations gives opportunity to produce stable and safe formulations with reduced amount of the $\mathrm{TiO}_{2}$ but high UV- protection ability (Cengiz et al., 2006).

SLN act as physical sunscreens, therefore, the concentration of potentially hazardous molecular sunscreen can be decreased while maintaining the sun protection factor. SLN are able to provide a sustained release carrier system, therefore the sunscreen remains longer on the surface of the skin where it is intended to act (Wissing et al., 2003a; Wissing et al., 2002). Thus concentration of UV blockers can be decreased. It was shown that physical and chemical sunscreens can be incorporated to the SLN formulations (Wissing, et al., 2001a). SLN-CP showed better UV protection and introduced as a good carrier for incorporating sunscreens and indicated better moisturizing effect by in vivo method.

\section{CONCLUSION}

The results showed that the SLN-CP has more ability to hydrate skin and protect skin against UV irradiation compared to SLN-GMS and SLN-P. The results also demonstrated that the crystallinity and occlusive factor of solid lipid besides some other factors can influence on skin hydration. Also the crystallinity of solid lipid in SLN formulations is more effective on UV- protection effects than the size of SLN. It was also indicated that the occlusive factor obtained by in vitro study does not simulate the skin hydration by in vivo study. These results showed that the SLN-CP could be a promising carrier for sunscreens and moisturizers.

\section{ACKNOWLEDGMENTS}

The authors would like to thank the School of Pharmacy and Nanotechnology Research Center of Mashad University of Medical Sciences for the financial support of this project. Technical assistance of Mrs M. Eskandari is appreciated.This study was a part of Pharm D thesis of Mohsen Mokhtari.

\section{REFERENCES}

ALANEN, E.; NUUTINEN, J.; NICKLEN, K.; LAHTINEN, T.; MONKKONEN, J. Measurement of hydration in the stratum corneum with the moisture meter and comparison with the corneometer. Skin Res. Technol., v.10, n.1, p.32-37, 2004.

CENGIZ, E.; WISSING, S.A.; MULLER, R.H.; YAZAN, Y. Sunblocking efficiency of various $\mathrm{TiO}(2)$-loaded solid lipid nanoparticle formulations(1). Int. J. Cosmet Sci., v.28, n.5, p.371-378, 2006.

DIFFEY, B.L. Human exposure to solar ultraviolet radiation. $J$. Cosmet. Dermatol., v.1, n.3, p.124-130, 2002.

GOLMOHAMMADZADEH, S.; JAAFARI, M.R.; KHALILI, N.; GREENOAK, G. Determination of SPF and moisturizing effects of liposomal and conventional formulations of octyl methoxycinnamte as a sunscreen. Irn. J. Basic Med. Sci., v.10, n.2, p.99-110, 2007.

HOU, D.; XIE, C.; HUANG, K.; ZHU, C. The production and characteristics of solid lipid nanoparticles (SLNs). Biomaterials, v.24, p.1781-1785, 2003.

JENNING, V.; GOHLA, S.H. Encapsulation of retinoids in solid lipid nanoparticles (SLN). J Microencapsulation, v.18, n.2, p.149-158, 2001.

KULLAVANIJAYA, P.H.; LIM, W. Photoprotection. J. Am. Acad. Dermatol., v.52, n.6, p.937-958, 2005.

KUMAR, V.V.; CHANDRASEKAR, D.; RAMAKRISHNA, S.; KISHAN, V.; RAO, Y.M.; DIWAN, P.V. Development and evaluation of nitrendipine loaded solid lipid nanoparticles: influence of wax and glyceride lipids on plasma pharmacokinetics. Int. J. Pharm., v.335, n.1-2, p.167-175, 2007.

LEVY, M.Y.; SCHUTZE, W.; FUHRER, C.; BENITA, S. Characterization of diazepam submicron emulsion interface: role of oleic acid. J. Microencapsulation, v.11, n.1, p.79-92, 1994.

LI, Z.; YU, L.; ZHENG, L.; GENG, F. Studies on crystallinity state of puerarin loaded solid lipid nanoparticles prepared by double emulsion method. J. Therm. Anal. Calorim., v.99, n.2, p.689-693, 2010. 
LIU, J.; HU, W.; CHEN, H.; NI, Q.; XU, H.; YANG, X. Isotretinoin-loaded solid lipid nanoparticles with skin targeting for topical delivery. Int. J. Pharm., v.328, n.2, p.191-195, 2007.

MAIA, C.S.; MEHNERT, W.; SCHAFER-KORTING, M. Solid lipid nanoparticles as drug carriers for topical glucocorticoids. Int. J. Pharm., v.196, n.2, p.165-167, 2000.

MULLER, R.H.; DINGLER, A. The next generation after the liposomes: solid lipid nanoparticles (SLNe, Lipopearlse) as dermal carrier in cosmetics. Eurocosmetics, v.7, n.8, p.19-26, 2000.

MULLER, R.H.; MADER, K.; GOHLA, S. Solid lipid nanoparticles (SLN) for controlled drug delivery - a review of the state of the art. Eur. J. Pharm Biopharm., v.50, n.1, p.161-177, 2000.

POTARD, G.; LAUGEL, C.; SCHAEFER, H.; MARTY, J.P. The stripping technique: in vitro absorption and penetration of five UV filters on excised fresh human skin. Skin Pharmacol. Appl Skin Physiol., v.13, n.6, p.336-344, 2000.

SATOR, P.G.; SCHMIDT, J.B.; HONIGSMANN, H. Comparison of epidermal hydration and skin surface lipids in healthy individuals and in patients with atopic dermatitis. J. Am. Acad. Dermatol., v.48, n.3, p.352-358, 2003.

SAUPE, A.; WISSING, S.A.; LENK, A.; SCHMIDT, C.; MULLER, R.H. Solid lipid nanoparticles (SLN) and nanostructured lipid carriers (NLC) - structural investigations on two different carrier systems. Biomed. Mater. Eng., v.15, n.5, p.393-402, 2005.

SOUTO, E.B.; MULLER, R.H. Cosmetic features and applications of lipid nanoparticles (SLN, NLC). Int. J. Cosmet. Sci., v.30, n.3, p.157-165, 2008.

SOUTO, E.B.; WISSING, S.A.; BARBOSA, C.M.; MULLER, R.H. Development of a controlled release formulation based on SLN and NLC for topical clotrimazole delivery. Int. J. Pharm., v.278, n.1, p.71-77, 2004.

VENKATESWARLU, V.; MANJUNATH, K. Preparation, characterization and in vitro release kinetics of clozapine solid lipid nanoparticles. J. Control Release., v.95, n.3, p.627-638, 2004.
VERMA, D.D.; VERMA, S.; BLUME, G.; FAHR, A. Particle size of liposomes influences dermal delivery of substances into skin. Int. J. Pharm., v.258, n.1-2, p.141-151, 2003.

WISSING, S. A.; LIPPACHER, A.; MULLER, R. Investigations on the occlusive properties of solid lipid nanoparticles (SLN). J. Cosmet. Sci., v.52, n.5, p.313-324, 2001.

WISSING, S.A.; MULLER, R.H. A novel sunscreen system based on tocopherol acetate incorporated into solid lipid nanoparticles. Int. J. Cosmet. Sci., v.23, n.4, p.233-243, 2001 a.

WISSING, S.A.; MULLER, R.H. Solid lipid nanoparticles (SLN)-a novel carrier for UV blockers. Pharmazie, v.56, n.10, p.783-786, $2001 b$.

WISSING, S.A.; MULLER, R.H. Solid lipid nanoparticles as carrier for sunscreens: in vitro release and in vivo skin penetration. J. Control Release., v.81, n.3, p.225-233, $2002 a$.

WISSING, S.A.; MULLER, R.H. The influence of the crystallinity of lipid nanoparticles on their occlusive properties. Int. J. Pharm., v.242, n.1-2, p.377-379, 2002 b.

WISSING, S.A.; MULLER, R.H. Cosmetic applications for solid lipid nanoparticles (SLN). Int. J. Pharm., v.254, n.1, p.65-68, 2003a.

WISSING, S.A.; MULLER, R.H. The influence of solid lipid nanoparticles on skin hydration and viscoelasticity--in vivo study. Eur. J. Pharm. Biopharm., v.56, n.1, p.67-72, 2003 b.

XIA, Q.; SAUPE, A.; MULLER, R.H.; SOUTO, E.B. Nanostructured lipid carriers as novel carrier for sunscreen formulations. Int. J. Cosmet. Sci., v.29, n.6, p.473-482, 2007.

ZHAI, H.; MAIBACH, H.I. Occlusion vs. skin barrier function. Skin Res. Technol., v.8, n.1, p.1-6, 2002.

ZUR MUHLEN, A.; SCHWARZ, C.; MEHNERT, W. Solid lipid nanoparticles (SLN) for controlled drug delivery--drug release and release mechanism. Eur. J. Pharm. Biopharm., v.45, n.2, p.149-155, 1998.

Received for publication on $15^{\text {th }}$ February 2012 Accepted for publication on $23^{\text {rd }}$ August 2012 